\title{
DIOGENES OF OENOANDA ON CYRENAIC HEDONISM
}

One of the reasons why the past three decades have been an exciting time for historians of Epicureanism has been the revival of work on the Herculaneum papyri - very much a team effort. But another equally good reason has been provided by a remarkable solo act, Martin Ferguson Smith's pioneering work on the second-century AD Epicurean inscription of Diogenes of Oenoanda - the largest of all Greek inscriptions to survive from the ancient world, a key text in the history of Epicurean philosophy, and an extraordinary snapshot of the (literally) monumental scale on which philosophical evangelism could be practised in the Roman empire.

Smith has, almost single-handed, discovered and edited well over 100 new fragments of the inscription. This enabled him in 1993 to publish his comprehensive edition of the augmented inscription. ${ }^{1}$ But that was not the end of his labours. Returning to the site of Oenoanda, he has unearthed a substantial body of new 'new fragments', and has hopes of uncovering more in future seasons. A recent batch was published in a 1998 article. $^{2}$ In this paper I want to consider just one of them, New Fragment 128, which fills a hole in the existing fr. 33 of Smith's edition. Thanks to this discovery, Smith has been able to supply the line-ends of the missing col. IV, and likewise to join the previously lost line-beginnings of col. $\mathrm{V}$ to the already surviving line-ends of that column. In addition, he has been able to make very convincing improvements to his previous readings of column III.

Frr. 32-3 are from Diogenes' ethical treatise. In fr. 28, which contains the title of the treatise, we can discover that it was an 'epitome', and also that it had the word $\pi a \theta \tilde{\omega} v$ in its title. We must recall that for an Epicurean the $\pi \dot{\theta} \theta \eta$ are not the passions, but the genus, 'feelings', of which pleasure and pain are the species. Hence the remains of the title can tell us no more than the unsurprising news that pleasure and pain will be among the principal topics of this Epicurean ethical epitome.

The next three fragments (29-31) seem to be introductory in content. But by the time he gets to 32 I 2-6 Diogenes has already embarked on the topic of virtue and pleasure: 'I shall talk about folly a little later. For now, my subject is the virtues and pleasure.' From this point on it becomes clear that he is in the process of attacking those who make virtue the end rather than the means to the end:

If, gentlemen, the agenda between these people and us involved the question 'What is it that produces happiness?', and they wished to say the virtues, which

2 Smith (1998). The material on NF 128 is found at pp. 146-52, with a brief 'postscript' on p. 166 responding to some of the ideas put forward in the present paper. 
is actually true, all I would need to do is to agree the point with them and leave it at that. But since, as I say, the agenda is not 'What is it that produces happiness?', but 'What is it that being happy consists in and that in the last analysis our nature desires?', my answer is pleasure, and I cry out loudly both now and always to all Greeks and foreigners alike that pleasure is the end of the best way of life. As for the virtues, which as it is these people inopportunely garble by transferring them from the place of that which is productive of happiness to that of the end, I say that they are by no means the end, but productive of the end. Let us then state the truth of this now, making the following start.

(32 I 6-III 11)

These opponents may be specifically the Stoics, as Smith maintains, or they may alternatively include all those who attach final value to virtue, including Socrates and Plato, and perhaps even (if slightly less accurately) Aristotle.

Diogenes continues at 32 III $11-$ IV 13:

If someone were to ask someone else, then, naive though the question may be, 'Who is it that these virtues benefit?', obviously he will reply: man. It's not, at any rate, on these birds flying past and on making them fly well, or on the individual members of the other animal species, that the virtues focus their care, thus abandoning the nature [i.e. human nature] with which they belong and by which they have been brought to birth. No, it is for the sake of that nature that they do everything, and that they exist.

I think we can see where the argument is heading. The Stoicising opponent, who advocates virtue as an end, has now been induced at least to agree that virtues exist for human benefit. The next question will be what benefit that might be? After a lost 8 lines, and a further 6 lines whose remains are hard to decipher, it is clear that Diogenes is answering his own question, what is the ultimate human good, to which virtue will turn out to be no more than a means? His words, from 32 VI 10 onwards, are (I am assuming a different supplement from Smith's in VII 2):

We must show which of the desires are natural and which not. And, taken as a whole, those which fall into the former category <will have as their target the natural good for man.>

It seems, then, that what started as an attack on the Stoics and perhaps on other champions of virtue as the end has now become an argument from first principles for Epicurean hedonism. The full reasoning will be this: virtue exists for the good of human nature, i.e. the natural human good; the natural human good must be whatever our natural desires aim for; but our natural desires aim for pleasure; therefore the natural human good is pleasure, and virtue exists for the sake of pleasure. 
But if I am right that Diogenes has now moved from anti-Stoic polemic into a positive argument for his own ethical position, what we find next may come as something of a surprise. After a substantial gap, which Smith reckons at around 11 columns, when the text resumes at 33 I 11 the Stoics seem still (or again?) to be the target. At 33111 an apparently Stoic concept, tonos, is introduced, and three lines later (on Smith's reconstruction) there follows a polemical remark about 'these sophists'. Then at II 2 even the name of 'Zeno himself' ${ }^{3}$ Must we really infer that these entire eleven columns pursued a specifically anti-Stoic agenda? Smith himself in his edition (p. 482) described this finding as 'remarkable'. I do not believe that we are obliged to accept it, but I must save my reasoning for later.

Next, at 33 II 9-III 8, in a very badly damaged passage, there is some talk about people running to pleasure, or virtue (II 9-12), and some people forgetting 'this hunger' (II 13-III 1). It is hard to make much headway with the task of integrating this into an overall argument. But we then come to the important passage 33 III 7-VIII 13. Smith takes it as still continuing the anti-Stoic polemic, and translates as follows:

(33 III 7) [...] is able, as these people lay it down, like a bait, for all human beings, to draw them, like birds or fish, open-mouthed to the names of the virtues, and sometimes (33 IV 1) <LACUNA OF THREE LINES> [illusions (?). And are you] not ashamed, [you] wretched people, [of contradicting yourselves and] one another: [for indeed, employing puerile] wit, [you reject] pleasure, while cleverly agreeing [with us about sensation], so that you are not [prevented from] passing through [an area in safety] when you venture to climb crags.

(33 V 2) Well now, I want to deflect also the error which, along with the feeling of self-love, has you in its grip - an error which, more than any other, further inflates your doctrine as ignorant. The error is this: [not] all causes in things precede their effects, even if the majority do, but some of them precede their effects, others [coincide with] them, and others follow them. ${ }^{4}$

3 Smith's text of 33 I 10-II 4 (but with some of his reported partial letter traces represented simply as dots):

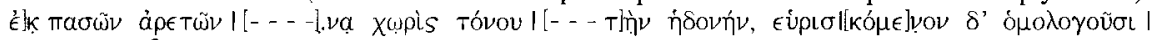

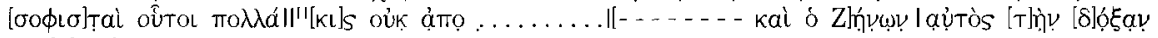

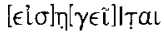

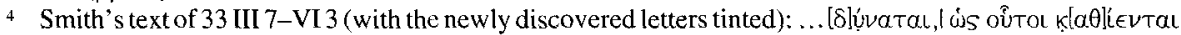

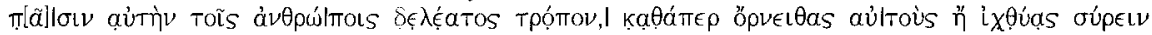

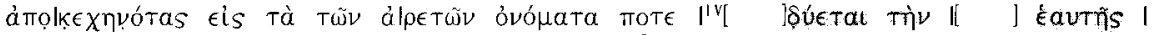

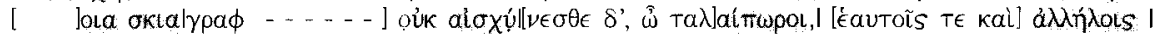

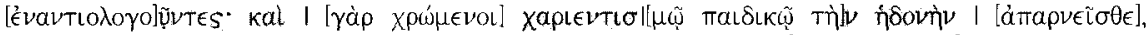

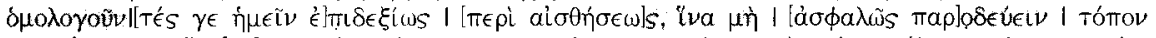

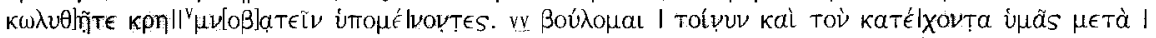

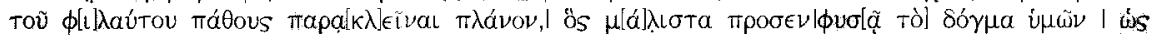
ả[ $[\mu a \theta]$ ]

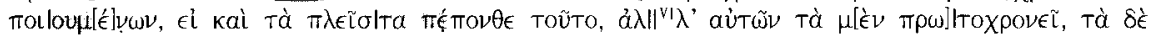

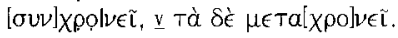


(33 VI 4) Examples of causes that precede are cautery and surgery saving life: in these cases extreme pain must be borne, and it is after this that pleasure quickly follows.

(33 VI 11) Examples of coincident causes are [solid] and liquid nourishment and, in addition to these, [sexual acts]: we do not eat [food] and experience pleasure afterwards, nor do we drink [wine] and experience pleasure afterwards, nor do we emit semen and experience pleasure afterwards; rather the action brings about these pleasures for us immediately, [without awaiting] the future.

(33 VII 11) [As for causes that follow, an example is expecting to win] praise after death: although men experience pleasure now because there will be a favourable memory of them after they have gone, nevertheless the cause of the pleasure occurs later.

(33 VIII 7) Now you, being unable to mark off these distinctions, and being unaware that the virtues have a place among the causes that coincide with their effects (for they are borne along with [pleasure), go completely astray].

Smith's general idea about the passage is as follows. It is in its entirety an anti-Stoic polemic, and focuses on the Stoic concept of oikeiôsis, our natural affinity for ourselves and others. The Stoics, he thinks, are first accused of offering oikeiôsis, or perhaps more specifically self-love, as a bait to lure people into virtue. Then, after a gap at IV $1-4$ which Smith leaves unreconstructed, they are accused of self-contradiction, in that they reject pleasure, yet at the same time agree with the Epicureans about the reliability of the senses, with Diogenes joking that they do this in order to ensure their own right to take the safest route when climbing crags. The alleged self-contradiction, Smith suggests, lies in the fact that the Stoics deny that pleasure is the end, yet endorse the senses, which in fact (according to the Epicureans, at least) provide the evidence that pleasure is the end. Then starting from V 2 Diogenes, after referring at lines 4-5 to a Stoic doctrine of self-love, adds a new charge: the Stoics think that all causes are antecedent, not realising that some are contemporaneous with their effects and some later than them. Why should this complaint be apposite to the Stoics? Smith's answer is that the Stoics are being accused of failing to grasp the Epicurean insight that virtue is the simultaneous cause of pleasure, and failing to grasp it because they mistakenly think all causes must precede their effects. He accepts the objection that this, if so, is a mistaken interpretation of Stoicism, which certainly held many causes to be contemporaneous with their effects; but he argues that Diogenes is quite capable of misrepresenting his opponents, and that there are Stoic doctrines - such as the doctrine that every event has an antecedent cause - which do lend themselves to the misinterpretation. (Of course, from the authentic Stoic premise that every event has an antecedent cause it does not follow that each event has exclusively antecedent causes. But perhaps Diogenes thought it did, Smith suggests.)

In support of this last point, Diogenes' propensity to unfairness, Smith refers us to a fuller discussion from his edition of Diogenes (pp. 128-31 and 137-8). But the very 
balanced remarks which he makes there do not really support the case. There is one famous instance (fr. 5 Smith) where Diogenes denounces Aristotle and the Peripatetics as extreme sceptics about the sensible world, owing to its rapid flux. But this is not a case of distortion or misrepresentation of an opponent's view. Rather, it is a simple mistake: he has confused the Peripatetics with someone else. And it is an isolated mistake. The one further case of alleged distortion is in fr. 16, where Diogenes denounces Protagoras' declared agnosticism as tantamount to atheism. Whatever one thinks of this inference (and I agree with Smith that for an Epicurean it may be a defensible one), it is explicitly Diogenes' own, and in no way involves a misrepresentation of what Protagoras himself said and held. So if in the present passage Diogenes is misrepresenting the Stoics as committed to the thesis that all causes are antecedent, that misrepresentation has no parallel in his text. The principle of charity dictates that we should give clear preference to an interpretation which avoids any such false attribution, if we are lucky enough to find one.

In any case, it remains mysterious why Diogenes should not only falsely attribute this causal thesis to the Stoics, but do so in the present context regarding the relation of virtue to pleasure. It is not a question of antecedence versus simultaneity. The Stoics did not think that there was any causal relation between virtue and pleasure. If they did not endorse the Epicurean thesis that virtue is the simultaneous cause of pleasure, that is not because they thought it was its antecedent cause instead, but because they did not concede that virtue leads to pleasure at all.

As far as I know, this is the only ancient text to propose the threefold division of causes into antecedent, simultaneous and retrospective, although it is a position which any Aristotelian could in principle have advocated (if retrospective causes were equated with final causes). Clearly it is not Diogenes' independent contribution to causal theory, but is meant to have an ethical point, specifically concerning the causes of pleasure. The examples used make this very clear, since they all without exception are examples of the causation of pleasure. Pleasures may have antecedent causes, like medical 'burning and cutting' (VI 5-6, examples stemming from the very similar defence of hedonism in Plato's Protagoras, 354a); they may have simultaneous causes, like eating, drinking and sex; and they may have causes which post-date the pleasures, such as the fame after death in whose anticipation some people take advance pleasure. At the end the accusation is made explicit: the opponents fail to realise that the virtues are the simultaneous cause of pleasure. What then do they believe? It is scarcely credible that they believe future virtue to be the cause of present pleasure, and in any case, given that they are accused of being incapable of distinguishing the three kinds of causes, it is hardly likely that they have made the highly refined move of individuating a class of retrospective causes. It is a near certainty, then, that the opponents hold virtue to be an antecedent cause of pleasure.

If so, they surely cannot be the Stoics, who consider pleasure a vice, and certainly do not recommend virtue as a means to it. It is true that, in Stoicism, the term 'pleasure' is sometimes used to describe not the passionate state of that name, but the simple 
sensation of pleasure that may arise naturally in any animal from eating, drinking or copulation. This latter kind of pleasure is an indifferent. It is not any animal's goal. It is merely, if it occurs at all, a 'by-product' marking nature's success, comparable to a plant's blooming (DL 7.85-6). Most Stoics denied (Cic. Fin. 3.17) that this kind of

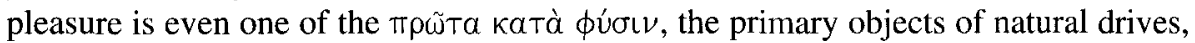
and certainly no Stoic ever thought it other than morally indifferent. In short, on no possible Stoic view of pleasure could it be said to have the direct causal correlation with virtue which is at issue in our passage of Diogenes.

I can see two prima facie plausible escape routes. One such route would be to suggest that in place of pleasure the Stoics are expected to nominate eudaimonia, or perhaps the good emotion (or eupatheia) called 'joy'. These are genuinely good states, which they really do believe to be the result of virtue. Against this suggestion, however, there is no way in which the Stoics could be suspected of making virtue merely the antecedent cause of these good states, and not their simultaneous cause.

The second escape route is as follows. Diogenes might be thought to mean that the Stoics, in criticising the Epicureans, misinterpret the Epicurean position that virtue is the cause of pleasure, and assume incorrectly that this must make virtue in the Epicureans' eyes temporally antecedent to pleasure. Diogenes would then be replying that causes do not have to be antecedent, and that if the Stoics had only realised this they would have had to abandon the criticism. Unfortunately the text does not lend itself to such a reading. The 'error' which Diogenes imputes to his opponents is explicitly one which, as he says at V 6-9, 'more than any other, further inflates your doctrine as an ignorant one'. That is, the causal error provides a substantial amount of specious content, not for the opponents' misrepresentation of the Epicurean position, but for the opponents' own ethical doctrine.

Smith further defends his thesis that the target is Stoic by appeal to col. IV, where the opponents are said to reject pleasure but to endorse the senses. However, this has no independent evidential value, because his restoration of col. IV is founded on the prior assumption that it has a Stoic target. By looking exclusively at the preserved letters on the right-hand side of col. IV, ${ }^{5}$ one can see that they offer no real support for any kind of Stoicising reconstruction, let alone the specific charge of self-contradiction (the

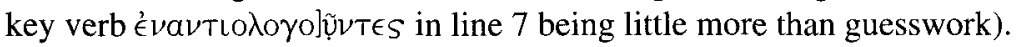

So far, my objection is not that the reconstruction of col. IV need be wrong, just that it is not evidence of anything. But as a matter of fact it does seem to me hard to accept as a reconstruction. Take the alleged self-contradiction, as proposed by Smith: the Stoics base knowledge on sense-perception, and yet do not make pleasure the end, even though our senses assure us (so the Epicureans believe) that it is the end. Only on an unusually relaxed understanding of the notion is that a self-contradiction. I cannot recall any piece of reasoning as feeble as this in the text of Diogenes, and we should surely

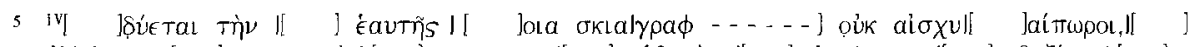

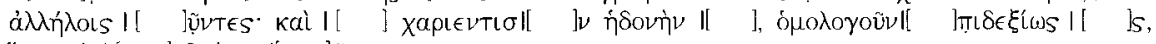

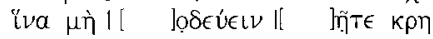


hesitate to invent one on his behalf. I shall save other doubts till a little later. First, let me try out an alternative interpretation, starting with the causal argument.

As we have seen, we are looking for a school which shares the Epicurean doctrine that virtue has instrumental value as a cause of pleasure, but which differs in making virtue an antecedent cause of pleasure, itself not intrinsically pleasant but instead related to pleasure more in the way that surgery is (VI 4-11). As far as I can see, the only possible candidates are the Cyrenaics. Apart from the Epicureans, they are the only ancient hedonist school, and, more specifically, the only school to recommend virtue on the grounds that it produces pleasure.

But given that the Cyrenaics share the Epicurean view that aretê is of instrumental rather than intrinsic value, is there enough of a gap between the two schools to permit the present disagreement? Yes, and a crucial one. Epicurus insists strongly on the simultaneity and inseparability of virtue and pleasure. As the Epicurean doxography at DL 10.138 puts it, 'Epicurus also says that virtue alone is inseparable from pleasure, while other things, such as food, do get separated from it.' 6 Epicurus' most famous assertion of this inseparability is at Ep. Men. 132:7

Of all these things, the starting-point and the greatest good is wisdom. Hence wisdom is more valuable even than philosophy, since the other virtues are its offspring. Wisdom teaches us that it is not possible to live pleasantly without living wisely and honourably and justly, nor to live wisely and honourably and justly without living pleasantly. For the virtues and living pleasantly belong naturally together, and living pleasantly is inseparable from the virtues.

From texts like these, Julia Annas has gone so far as to maintain that the Epicurean position on virtue is not instrumentalist at all. Rather, she argues (comparing Mill), virtue becomes part of the Epicurean pleasant life, and thus desirable for its own sake. ${ }^{8}$ This reading unfortunately requires her to dismiss a number of Epicurean texts - among them Diogenes of Oenoanda fr. 32 Smith - which insist that virtue has purely instrumental value and is never desirable for its own sake. And there is in any case something worrying about the reasoning. The only way I can see to understand Annas' interpretation is in terms of the following syllogism:

Living pleasantly is intrinsically desirable.

But living pleasantly is identical with living virtuously.

Therefore living virtuously is intrinsically desirable.

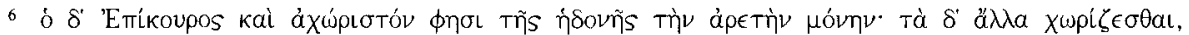
ốov BpwTá.

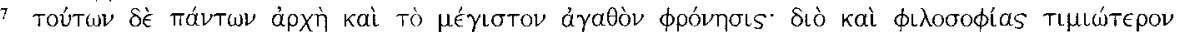

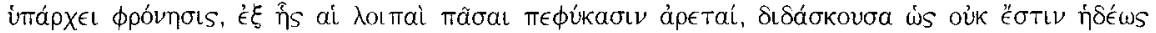

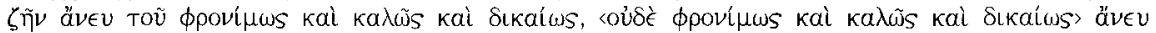

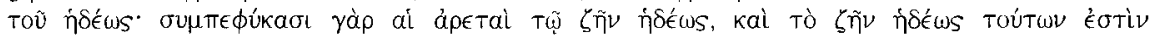
àxúplotov.

8 Annas (1993) 236-44. 
If this is what she means, the inference is surely fallacious. The predicate '... is intrinsically desirable' marks an intentional context, in which, as we now recognise, equivalent terms cannot always be substituted for each other salva veritate. To put the point a different way, the mere fact that $\mathrm{x}$ is identical with $\mathrm{y}$ does not rule out the possibility that one wants to have $x$ for the sake of having $y$, and not vice versa. For example, suppose we agree that money is both the major cause of human unhappiness and the basis of survival in the modern world. Despite this identity relation, it can still be the case that I desire to have the thing which is the major cause of human unhappiness for the sake of having the thing which is the basis of survival in the modern world, and not vice versa. Likewise, Epicurus is entirely justified in claiming both that living pleasantly is living virtuously, and that living virtuously has purely instrumental value in relation to living pleasantly.

No doubt Epicurus was no more aware of the rules about opaque-context substitutions than any other ancient thinker was, but here, as so often, his logical intuitions were sound ones. His ethical position seems to me entirely consistent on this score. The pleasant life and the virtuous life are one and the same, but when we ask what in that life makes it the most choiceworthy life, the answer is not the virtue per se but the resultant pleasure.

The inseparability of virtue from pleasure, on which Epicurus insisted, lies rather in the fact that the virtues, properly understood, are the skills of pleasure management, both short term and long term. Crucially, present pleasure can be derived from one's confident expectations about future pleasure. Thus if courage, justice and the other virtues are outlooks which exclude all fear of future pain and free you to look forward confidently to future pleasure, their very possession becomes pleasurable.

Could the Cyrenaics be interpreted as holding the mistaken view which Diogenes opposes to the Epicurean one, namely that virtue is merely the antecedent cause of pleasure, analogous to accepting painful surgery now for the sake of future pleasure? I am confident that they could, and in fact find much support for such a reading in Annas' persuasive treatment of the evidence for Cyrenaic ethics. ${ }^{9}$ We should note in particular DL 2.91:10 'They say that although wisdom is a good, it is choiceworthy not for its own sake but for the consequences ( $\tau \grave{\alpha}$... $\pi \epsilon \rho \iota \gamma \iota v o ́ \mu \epsilon v \alpha$ ) which follow from it.' Here 'consequences', $\pi \epsilon \rho \iota \gamma\llcorner\nu$ ó $\in \in \nu \alpha$, may seem insufficiently explicit. It might in principle correspond to the Epicurean version of instrumentalism, where pleasure is the intrinsic effect and simultaneous outcome of possessing wisdom and the other virtues. But it might, alternatively, describe a non-Epicurean version of instrumentalism, familiar from the consequentialist hedonism attributed to the 'many' in Plato's Protagoras, where courageous acts, abstemious acts and the like are not intrinsically pleasant but are valued for their future pleasant consequences. The latter, it seems, is what the Cyrenaic doctrine intends, as emerges when we compare a later

9 Annas (1993) 227-36.

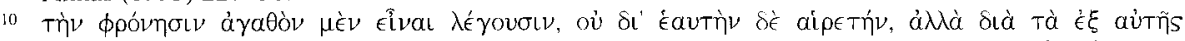

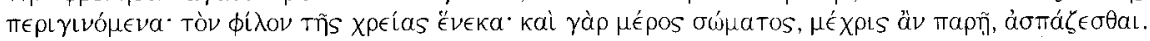


passage from the same Cyrenaic doxography (DL 2.96). ${ }^{11}$ The Annicereans -a leading Cyrenaic group precisely contemporary with Epicurus - are there said to emphasise that friendship and virtuous activity are likely to be frequently irksome, but worth while for the pleasures, even if few in number, which are their 'consequences':

The Annicereans ... allowed life to contain friendship, gratitude, honouring one's parents, and willingness to do something for the sake of one's country - things from which, as a result of this behaviour, although the wise man will undergo disturbances, he will none the less be happy, even if just a few pleasant feelings

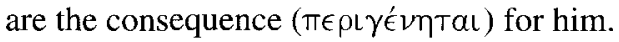

Here virtuous actions are admitted to be disagreeable for the sage, but are nevertheless said to contribute via their 'consequences' to his eudaimonia, which the Cyrenaics formally identify with the spread of pleasures over his lifetime (ib. 2.87). It seems then that the 'consequences' in question are long-term ones, and correspondingly that in Cyrenaic formulations the verb $\pi \epsilon \rho \iota \gamma i v \epsilon \sigma \theta a \iota$ represents after-effects, not concomitant effects. If so, both Cyrenaic texts point to a different kind of instrumentalism from Epicurus', one that fits well with the comparison of virtue to surgery.

That reading is supported by a key difference between the Epicurean and Cyrenaic positions. Where Epicurus, as I have said, attached special importance to the present pleasure that consists in anticipating future pleasures, the Cyrenaics expressly denied that this was possible. ${ }^{12}$ Their notional founder, Aristippus the Elder, had advocated living for the moment, and his more sober followers seem to have converted this into the more nuanced doctrine that, although it is prudent to plan for future pleasures and pain-avoidances, pleasures and pains are in themselves 'unitemporal' ( $\mu$ ovóxpovol, Athenaeus 544a-b, cf. DL 2.89-90), meaning that they can be actually enjoyed or suffered only at the time of their occurrence, and neither in anticipation nor in retrospect. This insistence reinforces the Cyrenaic thesis that, although the virtues by imposing present self-denial may help ensure our future pleasures, they can provide no actual pleasure now. It thus explains just why they would see virtue as analogous to surgery.

Now Epicurean hedonism was often accused of being barely distinguishable from the Cyrenaic version, and this charge is at least once made in connection with the two schools' instrumentalist doctrines regarding virtue. Cicero (Off. 3.116$)^{13}$ writes:

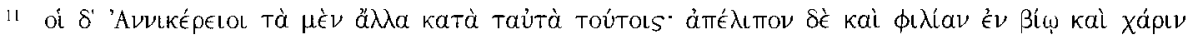

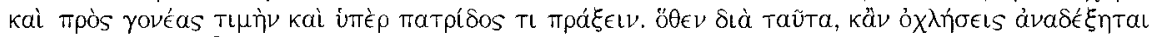

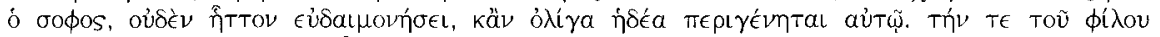

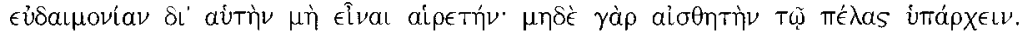


The Cyrenaic followers of Aristippus and the philosophers known as Annicereans located all good in pleasure, and thought that the reason why virtue should be praised was that it was the cause of pleasure. Although they have died out, Epicurus still flourishes, and he is the promoter and champion of what is more or less the same view.

This kind of accusation makes it all the more explicable that Diogenes should want to draw a line between the two schools' doctrines. He no doubt wants to emphasise that, according to the Epicureans, although it is true that virtue is valued not for its own sake but for the pleasure it produces, being virtuous is itself supremely pleasant; whereas, according to the Cyrenaics (as portrayed, at least), virtue is an irksome expedient, like surgery, which is recommended because it leads on to pleasure.

Try assuming that the opponents are Cyrenaics, then, and work backwards. At 33 V 2-9 we have, in Smith's new text, a crucial indication of the argument's structure:

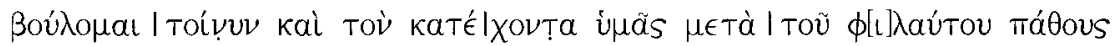

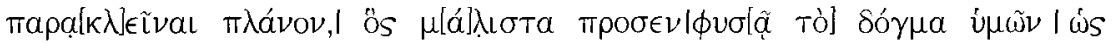

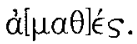

I want, therefore, to deflect the error which, along with ( $\mu \in T \alpha$ ) the self-loving feeling, has you in its grip - an error which, more than any other, further inflates your doctrine as an ignorant one.

What $\mu \epsilon T \alpha$ here introduces is not exactly the content of a doctrine, but a further failing listed as co-ordinate with the opponents' 'error'. The obvious meaning is that Diogenes earlier criticised them for this 'self-loving feeling', and is now turning to criticise a doctrinal error which they make in addition to it, or in combination with it. On the other hand, since the error 'further inflates' their doctrine as ignorant, the self-loving feeling has itself already made some contribution to their doctrine.

So what is the 'self-loving feeling'? Smith sees in it a reference to Stoic oikeiôsis, whose first manifestation in a new-born creature is indeed a kind of self-love, before, at least in humans, it extends itself into various forms of other-concern. If this were correct, it would I think have to be admitted that фí $\lambda$ avтos is not the Stoics' own term, but a disparaging description introduced by Diogenes. It is no accident that in our Stoic sources $\phi$ í $\lambda$ aUTOS and its cognates are never used in this connection, because the term is in the post-classical era invariably pejorative. Being фí $\lambda a u t o s$ standardly connotes an objectionable kind of self-regard or self-satisfaction. In any case, we want a

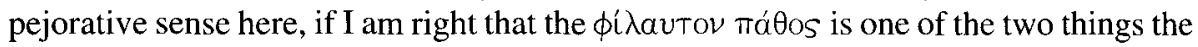
opponents are being accused of.

I cannot see any way of absolutely excluding a disparaging reference to Stoic oikeiôsis here, but, given my earlier argument that the opponents are in fact Cyrenaic 


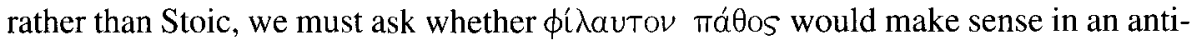
Cyrenaic context. It would make excellent sense. Diogenes Laertius reports as Cyrenaic doctrine that a friend is choiceworthy for the sake of utility, analogously to a part of one's own body. ${ }^{14}$ The Annicereans treat the value of friendship, along with virtuous conduct, in similarly instrumentalist terms. Significantly they remark: 'The happiness of one's friend is not choiceworthy for itself, for it is not even perceptible to a neighbour.' 15 This reasoning, as Annas notices, ${ }^{16}$ seems to rely on the Cyrenaic epistemological doctrine that the only things to which we can ever have cognitive access are our own $\pi \alpha \theta \eta .{ }^{17}$ You cannot value a friend's happiness as something intrinsically desirable, because you cannot even experience, let alone enjoy, your neighbour's happiness.

Here we have a Cyrenaic doctrine on friendship closely analogous to the one on virtue which we have already encountered, and it may well be what Diogenes has in his sights. According to the Epicureans, friendship entails putting a friend's pleasure on a par with your own, perhaps even ahead of your own. ${ }^{18}$ According to the Cyrenaics, in stark contrast, you cannot value a friend's own happiness for its own sake, and must instead treat a friend as a utility, a means to your own eventual pleasure, possibly at times even an irksome means. Hence, as a charge against the Cyrenaics, reference to a 'self-loving pathos' makes perfect sense. The Cyrenaics are accused of making their pathê, including pleasure, фí $\lambda a v T a$, 'self-loving', because they deny themselves the right ever to aim for and share a friend's pleasure. To an Epicurean eye, a Cyrenaic's

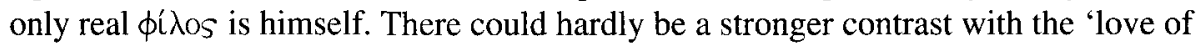

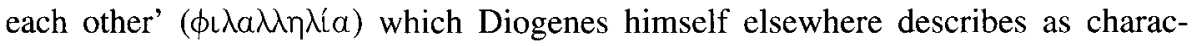
terising the future Epicurean golden age (fr. 56 Smith).

A further important structural point is that at $\mathrm{V} 2 \mathrm{ff}$. the new criticism of these opponents, for not realising that virtue is the contemporaneous cause of pleasure, follows from what precedes in the passage down to $\mathrm{V} 2$ (see text $\mathrm{n} .4$ above). This is the clear implication of toí $v v v$ in V 3. Smith takes Toívvv as merely progressive, but in Greek of this date (ubiquitously in Sextus Empiricus, for example) it standardly indicates that what precedes is the reason for what follows: if not 'therefore', at the very least 'then'. So we might expect him in those preceding lines to have been already deploring how, according to these opponents, virtue is a disagreeable necessity, valuable only because it leads on to pleasure. I think we can read the passage that way. Here is a rough shot at it:

14 See the end of the passage quoted in $\mathrm{n} .10$ above.

15 For the Greek see the end of the passage quoted in $\mathrm{n} .11$.

16 Annas (1993) 236.

17 On this aspect of Cyrenaic theory see the comprehensive study by Tsouna (1998).

18 The key text is Cicero, Fin. 1.66-70. 
[8]ựvatal,

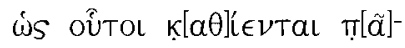

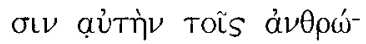

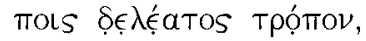

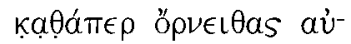
Toùs ที ix Đúas oúpeLv àmọ-

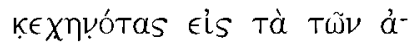
$\rho \in T \omega \tilde{\nu}$ óvónata, тоте́

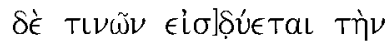
Sıávolav kaì] ÉavтT̃s $\gamma \rho a ́ \phi \in t \quad \pi \alpha v T$ ]oĩa $\sigma \kappa\left\llcorner\alpha^{-}\right.$

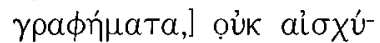

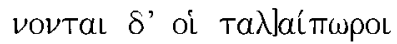

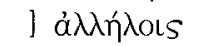
]ụvTES, kaì ] $\chi \alpha \rho L \in V T L \sigma^{-}$

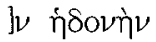

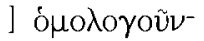
$\left.\epsilon^{\epsilon}\right] T \_\delta \in \xi i ́ \omega s$ ls iva $\mu$ ì

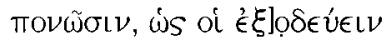

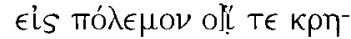

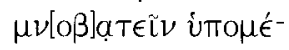
VOVTES.
$<$ Prospective pleasure $>$, as these people lay it down for all human beings like a snare, has the power to draw them like

III 10 birds or fish open-mouthed to the names of the virtues, and sometimes enters people's minds and paints all kinds of illusory pictures of itself, and the poor wretches are not ashamed <of

IV 1 bestowing favours on> each other, $<$ and charming people by their > wit, $<$ in pursuit of their own eventual> pleasure, agreeing adroitly <also to face dangers $>$ in order to avoid pain, like those who endure marching out to war and those who endure crag-climbing.

Smith's version, which we saw earlier (pp. 161-2), reconstructs IV 4-V 2 as outlining a Stoic self-contradiction: they reject pleasure, yet endorse the senses, which tell us that pleasure is the end. His reason for detecting a reference to the senses lies in his

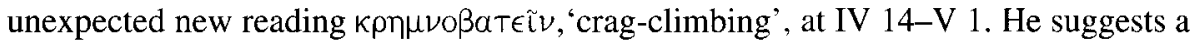
link with the Epicurean argument at Lucretius 4.507-10, where it is urged that if you could not trust your senses you would have no reason to avoid precipitous places praecipitosque locos vitare - and other perils. Smith, as we have seen (p. 161), reconstructs and translates these lines (IV 10-V 2) as follows: '... while cleverly agreeing [with us about sensation], so that you are not [prevented from] passing through [an area in safety] when you venture to climb crags.' I take him to mean by this that when the Stoics climb crags they want to be able to take the safe route, which requires trust in the senses. Can that be right? Crag-climbing, $\kappa \rho \eta \mu \nu о \beta \alpha \tau \epsilon \tilde{\imath} \nu$, is regularly regarded in the ancient sources as a difficult and dangerous activity requiring special skills. It is certainly an activity which most of us happily live without. The Lucretius passage, by contrast, says nothing about that activity, but is addressing modes of behaviour without which life would be impossible, including in this case our simple everyday preference for not getting too close to precipices and other hazards. 
If the passage is read roughly my way, on the other hand, the reference to cragclimbing finds a much closer parallel in the ancient sources. Sextus Empiricus ( $M$. $11.126)^{19}$ cites from unnamed ethical dogmatists the example of creatures who endure the distress of crag-climbing ( $\kappa \eta \eta \nu \circ \beta \alpha \tau \in \tilde{\nu} \nu$ ) in order to reach drink:

Thus, just as those creatures which climb crags in order to get a drink are driven to pleasure through painful means, and as soon as they have satisfied their desire cease from their former pains, so too man in his pursuit of the good necessarily suffers, but on achieving the object of his desire he is also released from his suffering.

The example is quoted precisely to illustrate the principle of accepting unpleasant means to pleasant ends. Crag-climbing is like surgery - exactly the kind of instrumentality which Diogenes wants to deny is operative when it comes to the relation of virtue to pleasure.

On my suggested reconstruction, the passage in cols. III-IV is a highly rhetorical attack on people who insidiously persuade us to put up with present pain or distress for the sake of deferred pleasures. The grammatical subject - unidentified, but referred to by the feminine pronoun $\alpha \dot{T}$ Tे $\nu$ at III 9 - is something which is able to draw people "to the names of the virtues' (i.e. to acquiring the reputation for virtue, rather than virtue itself), as the hunter's bait draws birds or fish to a snare. It is overwhelmingly probable

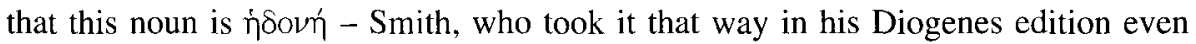
though he now prefers to detect a reference to Stoic self-love, has himself in his new article helpfully catalogued passages, from Plato onwards, in which pleasure is presented as a 'snare'. As for ovito in III 8, the simplest assumption is no doubt that these are the Cyrenaics, accused of using the prospect of pleasure to trick people into the appearance of virtue. On the other hand, there are at least two drawbacks to this assumption. First, it may be doubted whether seeking to make people behave in outwardly moral ways is something that would be imputed to the Cyrenaics by their critics. Second, the opponents next appear, at V 4, in the second person plural, and if that were a switch from previous use of the third person plural oifol one might expect Diogenes to indicate it by inserting a vocative, as he does elsewhere (7 II). A possibly preferable alternative, therefore, is that of tot refers not to the opponents but to legislators, politicians or educators, who tempt people into displays of virtuous conduct

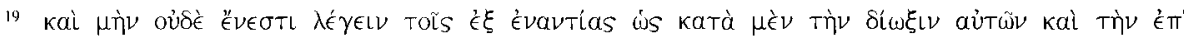

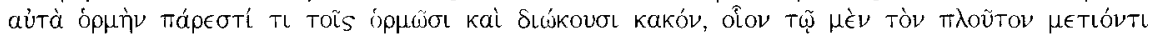

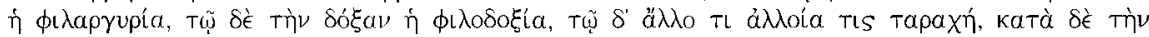

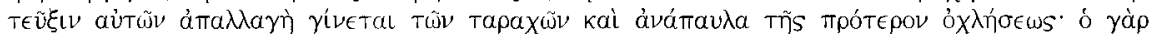

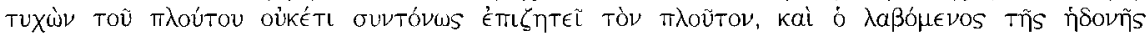

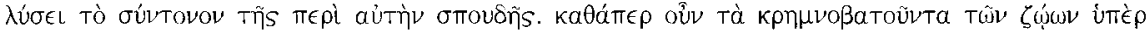

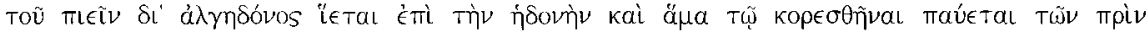

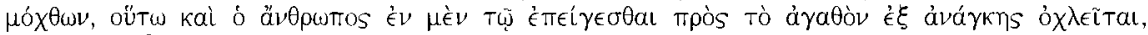

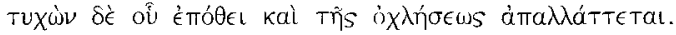


by promising them the deferred pleasure of future good reputation. Diogenes would on this reconstruction be attacking the Cyrenaic version of instrumentalism by comparing it to, or associating it with, the disagreeable image of educators and others who promise the deferred pleasure of fame, wealth or political power as a mere bribe to trick people into displaying virtuous conduct here and now.

Be that as it may, the remainder of col. IV, as I tentatively reconstruct it, scornfully describes other ways in which people will demean themselves, face perils, and so on, in return for the hope of a future pleasure. I have no particular faith in the details of my reconstruction, and have not even filled in more of the Greek than is strictly necessary in order to show how the text might deliver the kind of interpretation that $I$ have in mind. There is simply too little of this column surviving for any reconstruction to have probability on its side. My aim is merely to show that the column can, if desired, be read in such a way as to fit my overall interpretation. ${ }^{20}$

I now want to return to Smith's major objection: if these are the Cyrenaics, where were they first introduced? He is right that, if the beginning of fr. 33 col. II is still arguing against the Stoics, there is scarcely room for the Cyrenaics to have been named and shamed either in II 4-9 or III 2-7. But must we accept that a Stoic target is still in his sights in col. II? Clearly the name 'Zeno' at II 2 is too conjectural to carry weight (the first letter is missing, and the other four are all dotted): Smith's restoration of it is based on the prior belief that the context is Stoic. The main evidence lies rather in 33 I 10-12:

$$
\begin{aligned}
& {\left[\ldots \epsilon^{\prime}\right] \kappa \quad \pi \alpha \sigma \omega \tilde{v} \dot{\alpha} \rho \in T \omega \tilde{\omega} v} \\
& {[\ldots] . v a \text { xwpis tóvov }}
\end{aligned}
$$

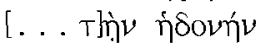

Smith writes:21

The reading $\chi \omega p \grave{s}$ Tóvov in I.11 is certain, and Tóvos here must surely be the 'tension', which, according to the Stoics, is a property of the $\pi \nu \in u ̛ \mu a$, the fiery breath which is the active principle interpenetrating the passive matter of the universe. For the Stoics the virtues involve the soul exhibiting the right degree of tension, while the passions involve lack of proper tension.

Now I agree that lack of proper pneumatic tension is a possible Stoic characterisation of vice. But to speak of something as without tension appears to make sense only in the

20 I much admire Martin Smith's work on Diogenes of Oenoanda, but he and I have long disagreed about the wisdom of the very extensive restorations he prints as part of his text. His discovery of the previously missing line beginnings for $33 \mathrm{~V}$ now illustrates the dangers. In Smith (1993) he restored most of these line beginnings, and two thirds of the restorations now prove to have been wrong. While some of the errors are minor or otherwise innocuous, they also include the following: at $33 \mathrm{~V} 9$, where Smith now

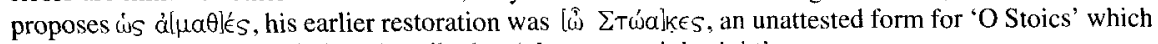
in his notes he had nevertheless described as 'almost certainly right'.

21 Smith (1998) 149. 
context of Stoic physics, where it is the two passive elements earth and water that are 'tensionless' (äTovol). It is hard to believe that any such topic occurred here in Diogenes' ethical treatise. $\chi$ wpis tóvov is a surprising expression, which, if only the context permitted, would normally be used to describe a word or letter as "unaccented'. Before racking our brains any further, we should go back for a moment to DL 10.138, 'Epicurus also says that virtue alone is inseparable from pleasure, while other things,

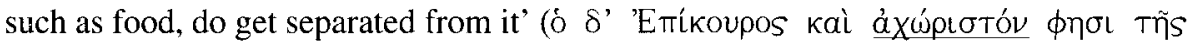

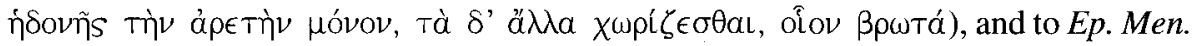
132 , 'For the virtues and living pleasantly belong naturally together, and living

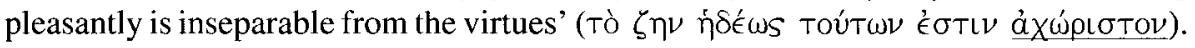
In the light of these passages, and of what we have seen to be the nature of the debate in which Diogenes is engaged, there is a much better way to divide and construe the sequence of letters I 10-12:

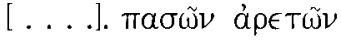

$$
\begin{aligned}
& \text { [ . . . ].v áxúplotov ôे- }
\end{aligned}
$$

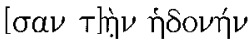

'... pleasure, which is inseparable from all virtues.' On such a reading, Diogenes is by this point already fully engaged in his argument against the Cyrenaics about the simultaneity and inseparability of virtue and pleasure. ${ }^{22}$

It is now clear that by the end of 33 I the Cyrenaics can perfectly well be the target. Since at $32 \mathrm{~V}$ the opponents were still people who uphold virtue as the end, and since it is hard to fit the switch from them to the new Cyrenaic target into the nine lost lines at the beginning of col. VI, it is safer to assume that it occurred somewhere after $32 \mathrm{VI}$ and before 33 I 9, a lacuna of about eleven columns according to Smith's calculation. Eleven columns is equivalent to some 150 lines, and thus to around 600 words - ample space for one or even more changes of topic.

Some conclusions. In this part of his ethical treatise Diogenes was especially concerned with demonstrating the correct relation of virtue to pleasure. Having dealt in fr. 32 with those who wrongly make virtue itself the end, he turned in the lost part between frs. 32 and 33 to those who rightly make pleasure the end but who misconceive its causal relation to virtue; that is, to the Cyrenaics. Their fault is twofold. (1) By denying us access to other minds, they eliminate other-concern and reduce friendship to a selfserving utility. (2) Likewise, they make virtue itself a mere utility, an antecedent cause of pleasure, not itself intrinsically pleasant but related to pleasure more in the way that

22 If that is right, the subject of the next sentence (I 12-II 1, for which see Smith's text in note 3 above)

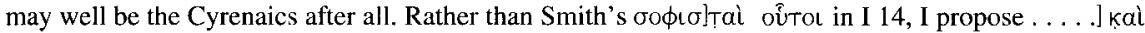
oûtol, and Smith has kindly confirmed that this is palaeographically possible. If so, we may perhaps

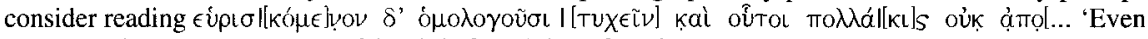
these people agree as a matter of fact it is found that often they are not $<$ far separated $>$...' 
surgery or crag-climbing is. To hold out future pleasure as a reward for virtue conjures up a repellent image of people hoodwinked into putting up with disagreeable duties and demeaning behaviour in the short term in the hope of future gratification. And it misses the true relation between virtue and pleasure, which is one of simultaneity and inseparability. The Cyrenaics fail to see this because they make the fallacious inference propter hoc ergo post hoc. The truth is that virtue and pleasure are simultaneous, because being virtuous is itself supremely pleasant.

This positive lesson about the immediate pleasantness of virtue undoubtedly lies at the heart of Diogenes' moral address to the citizens of Oenoanda. But why, in teaching it, would he target the Cyrenaics, a school defunct for the last four centuries? Now it is a well-recognised fact that Epicurus' own hedonism had been shaped largely by his reactions to contemporary Cyrenaic hedonism - in his eyes, just the sort of doctrine that gets hedonists a bad name, and therefore one in need of careful correction. Thus the doxographies contain a good deal of comparison and contrast between the Cyrenaic and Epicurean schools, and in Diogenes' ethical treatise too there is another fragment (49 Smith) containing a further attack on the Cyrenaics, under the name of their founder Aristippus, for privileging bodily pleasures and pains over mental ones. It is a virtual certainty that in frr. 32-3, as so often, what we are witnessing in Diogenes is a reversion to his school's foundational scriptures. His polemic against the Cyrenaics - like his criticisms elsewhere of Democritus and others - will either directly or indirectly be echoing Epicurus' critical writings. If I am right we have here, as a bonus, evidence that Epicurus' own instrumentalist doctrine on the inseparability of virtue and pleasure was originally formulated as a correction of the Cyrenaics. ${ }^{23}$

CHRIST'S COLLEGE, CAMBRIDGE

DAVID SEDLEY

\section{BIBLIOGRAPHY}

Annas, J. (1993) The morality of happiness, Oxford.

Smith, M. F. (1993) Diogenes of Oinoanda. The Epicurean inscription, Naples.

(1998) 'Excavations at Oinoanda 1997: the new Epicurean texts', Anatolian Studies 48, 125-70.

Tsouna, V. (1998) The epistemology of the Cyrenaic school, Cambridge.

Warren, J. (2001) 'Epicurus on the pleasures of the future', Oxford Studies in Ancient Philosophy 21, 135-79.

23 Versions of this paper have benefited from the comments of audiences at the London Institute of Classical Studies, the University of St Andrews, the Cambridge Philological Society, and the University of Toronto, and from additional comments supplied by Martin Ferguson Smith, Voula Tsouna and Peter Woodward. If in some cases I have failed to follow their advice, the blame is entirely mine. 